\title{
Continuing professional development opinions and challenges experienced by radiographers in KwaZulu-Natal Province, South Africa
}

\author{
K Naidoo, ${ }^{1}$ MHSc: Radiography, BTech: Radiography (D), NDip: Radiography (D); S Naidoo, ${ }^{2}$ MASc (MRT), BTech: Radiography (NM) \\ ${ }^{1}$ Department of Medical Imaging and Radiation Sciences, Faculty of Health Sciences, University of Johannesburg, South Africa \\ ${ }^{2}$ Department of Dental Science, Faculty of Health Sciences, Durban University of Technology, South Africa
}

Corresponding author: K Naidoo (kathleenn@uj.ac.za)

\begin{abstract}
Background. Continuing professional development (CPD) was introduced as a method to ensure that healthcare professionals continuously update their knowledge and skills. In South Africa (SA), CPD has been adopted as a mandatory requirement by the Health Professions Council of SA (HPCSA) for all registered healthcare professionals. However, despite CPD being mandatory, a number of healthcare professionals nationally are still non-compliant. Hence, research was conducted to determine the reasons for non-compliance.

Objective. To identify the opinions and challenges related to CPD compliance by radiographers working in KwaZulu-Natal (KZN) Province, SA.

Methods. A positivist paradigm and cross-sectional research design were used. The methodology was quantitative and the measuring instrument was a survey questionnaire. The majority of questions were closed-ended and a few were open-ended. The latter questions allowed participants to make suggestions and give opinions freely. Radiographers from all four disciplines in radiography, working in KZN, were included in this study. Quantitative data were analysed using SPSS version 23.0 (IBM Corp., USA). Open-ended questions were assessed qualitatively by means of coding and thematic analysis.

Results. This study revealed that the two most common challenges experienced by KZN radiographers were lack of time and the inability to attend CPD activities owing to shift work. The majority of participants acknowledged the importance of CPD; however, most indicated engagement with CPD only because of mandatory requirements by the HPCSA. This could imply a need to review the effectiveness of the current CPD processes.

Conclusion. In a profession such as radiography, which is constantly evolving and progressing, the need for CPD is indisputable. It is evident from the findings of this study that KZN radiographers acknowledge the importance and value of CPD in their profession. However, they experience a number of challenges that negatively affect their CPD participation. These challenges need to be addressed to ensure that the aim of CPD is achieved.
\end{abstract}

Afr J Health Professions Educ 2018;10(4):210-214. DOI:10.7196/AJHPE.2018.v10i4.1001

Dr Margaret Chan, Director-General of the World Health Organization (WHO), is in support of activities associated with the 'transforming and scaling up of health professionals' education and training. ${ }^{[1]}$ Globally, there is a health workforce crisis in terms of human resource shortages, as well as an imbalance in the skills mix. ${ }^{[1]}$ This imbalance is not only applicable to students and graduates, but also to employed radiography professionals. ${ }^{[2]}$ Enhancing or improving the skills mix has to be a lifelong learning practice for employed radiographers because they need to stay informed of the current changes in the health services environment. ${ }^{[3]}$ One of the ways in which this can be achieved is for individuals to engage in continuing professional development (CPD) activities. ${ }^{[4]}$

'The South African Health Professions Act, 1974 (Act No. 56 of 1974) (as amended) endorses CPD as the means for maintaining and updating professional competence, to ensure that the public interest is always promoted and protected, as well as ensuring the best possible health care service to the community. ${ }^{\text {[5] }}$ The Health Professions Council of South Africa (HPCSA) CPD guidelines ${ }^{[5]}$ highlights that CPD activities must be pertinent to the health priorities of the country and focus on the emerging health needs of the population. Therefore, the HPCSA implemented a CPD programme to ensure consistent and continuous commitment to lifelong learning by all health professionals. During the course of 1 year a total of 30 continuing education units (CEUs) must be accumulated, 5 of which must be related to ethics, human rights and medical law. The HPCSA conducts random mandatory audits to ensure compliance with the CPD programme. It has been noted, however, that $>50 \%$ of radiographers and clinical technologists (RCTs) who were audited from July 2009 to January 2013 were considered non-compliant (Appendix ${ }^{\star}$ ). Non-compliance is the failure of a healthcare professional to meet their annual CPD requirements. ${ }^{[5]}$

Non-compliance is of great concern, as it may result in a radiographer enduring penalties or even being suspended from the HPCSA register. Radiographers who are non-compliant may experience challenges. There needs to be an understanding of these perceived challenges encountered by healthcare professionals to have effective educational and training programmes that support professional development. ${ }^{[6-10]}$ The most common challenges that have been identified in the literature include, but are not limited to, lack of CPD awareness, funding, time, employer support and increased family commitments.

Reasons for non-compliance among radiographers in KwaZulu-Natal (KZN) Province, SA, are unknown and the literature on CPD compliance by radiographers in SA is scarce. The aim of this study was to identify the opinions and challenges related to CPD compliance by radiographers working in KZN and to ascertain their suggestions for improvement to CPD practices for recommendations to the HPCSA.

\section{Methods}

This research followed a quantitative, descriptive and cross-sectional research design. 


\section{Population and sampling}

The HPCSA online register, which is available to the public, was used to identify the participants. Only radiographers who worked in KZN were invited to participate. At the time of the study, there were $\sim 1200 \mathrm{KZN}$ radiographers registered with the HPCSA. The entire population was sampled, using the total population sampling technique to ensure a maximum return rate. The statistically acceptable sample size as calculated by a statistician was 292 radiographers. Only 146 of the 292 questionnaires were returned. This provided a response rate of $50 \%$.

\section{Data collection}

The data collection instrument comprised an online questionnaire. Closed-ended questions were used to answer the constructs on 'radiographers' opinions of CPD' and 'radiographers' CPD challenges experienced'. Open-ended questions were used to gain insight into the participants' suggestions for overcoming the identified CPD challenges. SurveyMonkey was selected as the online platform of choice. The privacy policy of the online survey website indicates that all data and email addresses are kept securely. ${ }^{[1]}$

Validity of the study was ensured, as the researcher developed the questionnaire design and structure after an extensive literature review of previous studies. ${ }^{[12]}$ The questionnaire was piloted by 14 radiography professionals, who were excluded from the main study. The aim of the pilot study was to ensure content validity. Recommendations were considered and minor amendments were made to the main questionnaire before final distribution. Data collection was conducted from May to July 2015 in KZN. An invitation to participate in the study was sent to KZN radiographers, who were contacted directly, via email, in their personal capacity.

\section{Data analysis}

Quantitative data were analysed by means of descriptive statistics to determine the frequency and means of data. The quantitative data collected from the questionnaire responses were analysed using SPSS version 23.0 (IBM Corp., USA).

To compare sets of data that are in the form of frequencies, $\chi^{2}$ tests were used. ${ }^{[12]}$ To determine whether the scoring patterns per statement were significantly different per option, a $\chi^{2}$ test was done. This is represented by $p$-values. If $p<0.05$, it implies that the distributions were not similar. Reliability testing was conducted using Cronbach's alpha coefficient test. The pilot study and the main study were analysed using Cronbach's alpha. Each construct achieved a value $>0.600$, which indicated a high degree of acceptable, consistent scoring for the various relevant sections of the research.

The qualitative data were reviewed to develop themes based on the overall understanding of the data. Summaries were created based on participants' answers and similar concepts were combined. ${ }^{[13]}$ Once themes were identified, the data were reviewed for supporting verbatim quotes.

\section{Ethical approval}

Ethical approval for the study (ref. no. REC 12/15) was obtained from the Institutional Research Ethics Committee at the Durban University of Technology (DUT). Study participation was voluntary and participants could withdraw from the study at any time. Consent for the study was obtained electronically, as the participant followed the web link to complete the questionnaire.

\section{Results}

From 292 questionnaires, 146 (50\%) were completed and available for analysis.
Fig. 1 illustrates the construct on radiographers' opinions of CPD. The majority of respondents (74.66\%; $p=0.000$ ) agreed that CPD is important and improves knowledge (90.42\%; $p=0.000$ ). Interestingly, more than half of the respondents disagreed with the statement that CPD is not costly to the practitioner $(p=0.000)$. More than half of the respondents $(76.71 \% ; p=0.000)$ engaged in CPD only because it is a requirement of the HPCSA.

It is important to note that the majority of respondents agreed that CPD should be linked to both developmental and professional needs ( $p=0.000$ ) (Fig. 2). Furthermore, most respondents agreed that $\mathrm{CPD}$ should be provided by in-house training $(p=0.000)$ and that it should be conducted during working hours $(p=0.000$ ). Respondents were hesitant towards compulsory CPD, with only $45.8 \%$ of respondents agreeing on this $(p=0.001)$.

Table 1 depicts the extent to which various factors affected CPD participation. The construct on 'radiographers' CPD challenges experienced' revealed two major factors that affected $\mathrm{CPD}$ participation to a great extent, i.e. lack of time

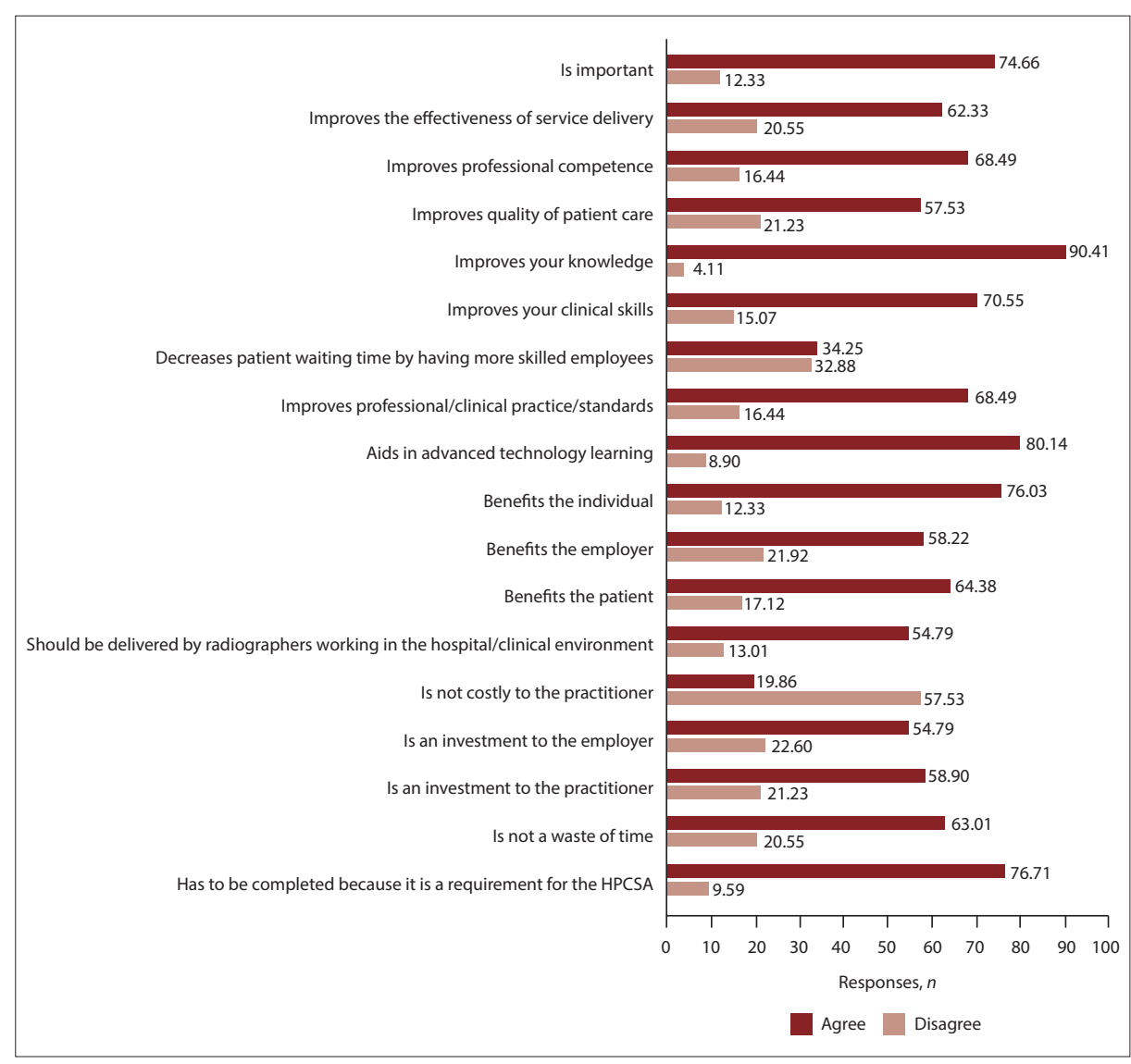

Fig. 1. Responses with regard to opinions on continuing professional development. (HPCSA = Health Professions Council of South Africa.) 
(46.5\%) and inability to attend CPD activities due to shift work (47.2\%). Another significant factor affecting CPD participation was the lack of employer support in terms of funding (34.9\%), time (36.3\%) and motivation (21.9\%). The factors that least affected CPD participation were lack of understanding of what is required (54.1\%) and inaccessibility to technological facilities (47.9\%).

The responses to accessibility of resources are shown in Table 2.

The majority of respondents (91.1\%) had access to the internet $(p=0.000)$, but more than half $(58.9 \%)$ did not have access to funding to attend CPD workshops or seminars $(p=0.031$ )

Results from the open-ended questions are given here. Participants were asked for suggestions to overcome their identified CPD challenges. Most agreed that support should be provided for CPD engagement $(p=0.000)$. The majority (84.14\%) agreed that study leave should be provided to attend seminars, workshops and conferences $(p=0.000)$. Respondents were also in agreement that employers should have formal policies to support CPD financially (94.48\%; $p=0.000)$ and CPD update courses should be made available ( $94.48 \% ; p=0.000)$.

Suggestions to address the challenges related to CPD compliance included the following:

- Provision of funding should be allocated.

- Provision of time should be allocated.

- There should be an increased accessibility to CPD activities.

- There should be an increase in employer involvement.

- Improved locations for CPD activities should be addressed.

- There should be an increased awareness of CPD.

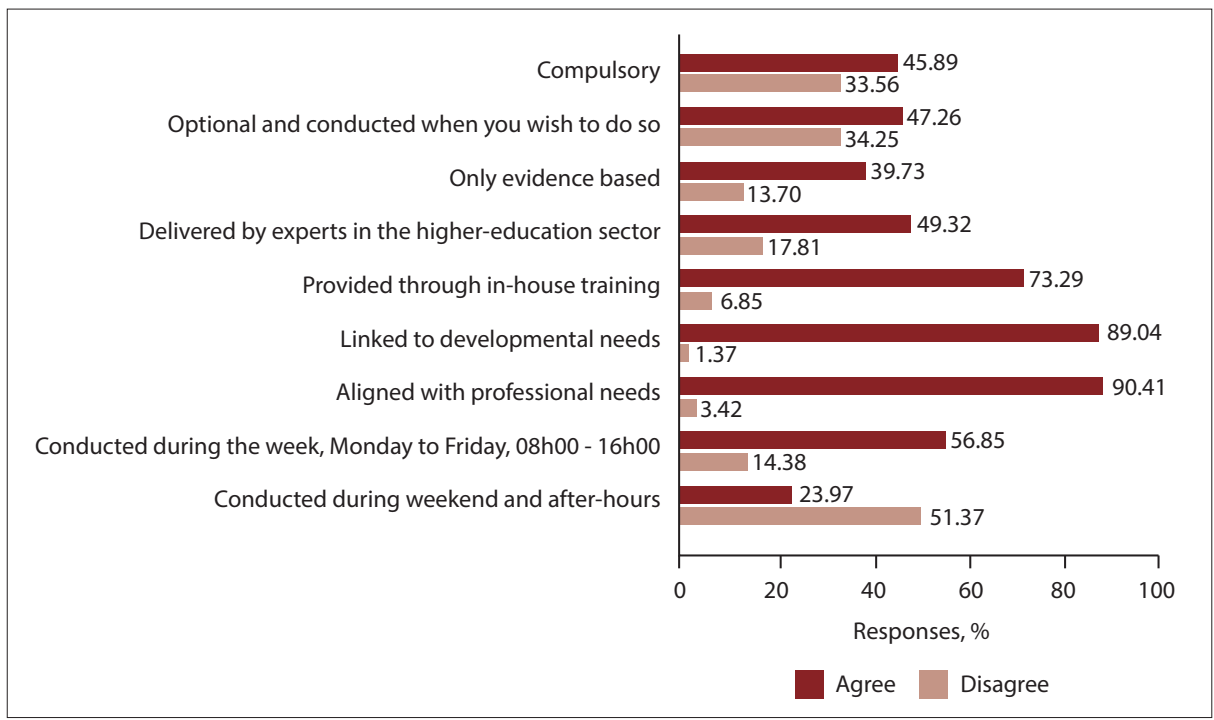

Fig. 2. Responses with regard to opinions on continuing professional development implementation.
- The HPCSA's involvement with practitioners should be increased.

Most of the respondents considered the provision of funding to be a method to overcome CPD challenges, while others considered increased accessibility of CPD activities to be a means of overcoming some of the challenges. Respondents were also requested to provide suggestions with regard to ways to improve the $\mathrm{CPD}$ auditing process. The common themes that emerged were as follows:

- systematic audit method

- improvement of HPCSA's communication

- extended time for CEUs

- increase in audit awareness.

Some participants expressed negative feelings towards CPD audits and suggested 'the doing away of audits. The majority of participants expressed the need for an online system for uploading certificates directly to the HPCSA website for regular monitoring whenever the need arises.

\section{Discussion}

There was a clear indication by participants that CPD is important and beneficial for improving an individual's knowledge. There were similar findings among radiographers in Sudan, Europe and Australia. ${ }^{[3,9,14,15]}$ Despite the recognised importance of CPD by the participants in this study, they also indicated that they took part in CPD activities owing to mandatory HPCSA requirements. Unfortunately, this is an indicator of a 'tick-box' mentality that was identified in international studies, whereby individuals undertake CPD to fulfil regulatory obligations. ${ }^{[16,17]}$ This mentality defeats the purpose of CPD and

Table 1. Responses to the extent to which factors have affected participation in CPD activities

\begin{tabular}{lllll}
\hline Responses & Not at all, \% & Least extent, \% & Some extent, \% & Great extent, \% \\
\hline Lack of time & 8.2 & 3.4 & 41.8 & 46.6 \\
Lack of funding and financial support for CPD & 13.0 & 13.7 & 37.0 & 36.3 \\
Lack of employer/management support in terms of funding & 17.1 & 17.8 & 30.1 & 34.9 \\
Lack of employer/management support in terms of motivation & 26.7 & 19.9 & 31.5 & 21.9 \\
Lack of employer/management support in terms of allocating time for CPD & 16.4 & 17.1 & 30.1 & 36.3 \\
Inability to participate in CPD activities because of shortage of staff & 11.6 & 19.9 & 28.1 & 40.4 \\
Unable to attend CPD activities because of shift work & 18.5 & 11.0 & 23.3 & 47.3 \\
Lack of understanding of what is required & 54.1 & 27.4 & 13.0 & 5.5 \\
Inaccessibility of technological facilities & 47.9 & 26.7 & 15.1 & 10.3 \\
Commitments outside work limit time for participation & 12.3 & 24.7 & 33.6 & 29.5 \\
Difficulty keeping own records up to date & 41.8 & 26.0 & 18.5 & 13.7 \\
No help from HPCSA when required & 32.2 & 24.7 & 18.5 & \\
CPD = continuing professional development; HPCSA = Health Professions Council of South Africa. & & & &
\end{tabular}


Table 2. Responses to accessibility of resources

\begin{tabular}{ll}
\hline Responses & Frequency (\%) \\
\hline Internet & $133(91.1)$ \\
Peer-reviewed journals & $93(63.7)$ \\
Opportunities to undertake CPD activities & $114(78.1)$ \\
Transport to attend CPD activities & $100(68.5)$ \\
Funds to attend CPD workshops/seminars & $60(41.1)$ \\
CPD = continuing professional development. &
\end{tabular}

has no value with regard to professional or individual development. Therefore, there are ongoing debates on the effectiveness of mandatory CPD. ${ }^{[14,15]}$ Some international authors recommend that CPD be based on outcomes rather than the number of hours or points attained. ${ }^{[18]}$ While these findings are based on a smaller professional sample, further investigations into whether other professionals display similar attitudes could be valuable for review of the current CPD system.

The two main contributors that affected CPD participation in this study were a lack of time and the inability to attend CPD activities due to shift work. Another significant factor that is closely related to these two factors was a lack of support from employers in terms of the provision of funding, time and motivation. Similar findings were illustrated in radiography research studies in Sudan, Namibia and the UK ${ }^{[3,4,19]}$ However, participants from the UK were unable to suggest strategies to overcome the challenge of limited time, but did indicate a need for 'protected', dedicated time to engage in CPD activities. ${ }^{[4]}$

The impact of shift work on CPD activities is a critical factor. However, finding a balance between work commitments and time to engage in CPD activities is necessary. In Namibia, radiographers indicated that they preferred CPD involvement during their leisure time. This was in contrast to findings from KZN radiographers, who preferred CPD to be conducted during the week (between $08 \mathrm{~h} 00$ and 16h00).

A significant number of participants in this study agreed that employers should have formal policies to support the financial implications of CPD. The Namibian radiographers displayed comparable findings for a need for management support funding of CPD activities. ${ }^{[19]}$ Globally, CPD funding continues to be a major challenge for healthcare professionals. Similarly, in this study more than half of the participants did not have access to funds for CPD engagement. This, however, seems to be a greater challenge among public-sector employees than those in the private sector. Since the introduction of mandatory CPD in Australia, the government has provided staff with financial support and leave to participate in CPD activities. ${ }^{[20]}$ Because of mandatory CPD in SA, it could be recommended that the government consider incorporating methods to assist with the financial implications of CPD.

As many individuals considered lack of time as a challenge when required to participate in $\mathrm{CPD}$ activities, engaging in reflective practice is highly recommended in literature ${ }^{[9]}$ Education is regarded as ongoing and cannot be a once-off experience. Therefore, individuals need to have a deep, meaningful approach to learning, which can be achieved through reflective practice. ${ }^{[21]}$ Work-based learning is encouraged and was noted to be very beneficial, as it provided more flexibility for the professional. ${ }^{[9]}$ This reduces the need to take time off from work to attend CPD activities. ${ }^{[9]}$ Work-based learning is a method that radiography employers could consider to assist radiographers in achieving $\mathrm{CPD}$ goals.
The literature also illustrates that there is a lack of time for the recording and evidence-keeping of CPD activities. ${ }^{[10]}$ This challenge has been overcome by many professional councils and institutes implementing an online CPD recording system for their members. ${ }^{[22-24]}$ The SA Institute of Chartered Accountants (SAICA) and the Pharmaceutical Society of Northern Ireland provide their members with two options for the recording of CPD engagement - paper-based and online. However, both societies clearly state that their preferred method is the online facility. ${ }^{[23,24]}$ The online database provides members with convenient and easy safe-keeping of all CPD activities - thus reducing the time required for manual recording. Similarly, the participants of this study suggested having an online CPD recording system as a strategy to improve the CPD auditing process. This method of CPD recording is a suggestion for the HPCSA to consider and could prove valuable to improving $\mathrm{CPD}$ audits.

\section{Conclusion}

In a profession such as radiography, which is constantly evolving and progressing, the need for CPD is indisputable. It is evident from the findings of this study that KZN radiographers acknowledge the importance and value of CPD within the profession of radiography. However, they do experience a number of challenges that affect their CPD participation. They also find themselves in an environment that does not fully support their professional development. These identified challenges, if not addressed, may negatively affect CPD participation and the efficiency of service delivery.

${ }^{*}$ The Appendix is available from the corresponding author on request.

\section{Declaration. None.}

Acknowledgements. The authors would like to thank all participants for their contribution to this study.

Author contributions. Both authors contributed equally to the article.

Funding. Financial assistance was received from the Faculty of Health Sciences at the University of Johannesburg.

Conflicts of interest. None.

World Health Organization. Guidelines. Transforming and scaling up health professionals' education and trainin 2013. http://apps.who.int/iris/bitstream/10665/93635/1/9789241506502_eng.pdf (accessed 5 November 2018).

2. Wareing A, Buissink C, Harper D, et al. Continuing professional development (CPD) in radiography: A collaborative European meta-ethnography literature review. Radiography 2017;23:S58-S63. https://doi.org 10.1016/j.radi.2017.05.016

3. Elshami W, Elamrdi A, Alyafie S, Abuzaid M. Int J Med Res Health Sci 2016;5(1):68-73. https://doi.org/10.5958/2319 5886.2016.00015.1

4. Stevens BJ, Wade D. Improving continuing professional development opportunities for radiographers: A single centre evaluation. Radiography 2017;23(2):112-116. https://doi.org/10.1016/..radi.2016.12.001

5. Health Professions Council of South Africa. Continuing professional development guidelines for the health care professionals. 2017. http://www.hpcsa.co.za/Uploads/editor/UserFiles/downloads/cpd/CPD_Guidelines Sept_2017.pdf (accessed 5 November 2018).

6. Ikenwilo D, Skatun D. Perceived need and barriers to continuing professional development among doctors Health Pol 2014;117(2):195-202. https://doi.org/10.1016/j.healthpol.2014.04.006

7. Mizuno-Lis S, Kono K Leal . Mizuno-Lewis S, Kono K, Lewis DR, et al. Barriers to continuing education and continuing professiona development among occupational health nurses in Japan. Workplace Health Safety 2014;62(5):198-205. https:/
doi.org/10.3928/21650799-20140422-03

8. Gawugah JNK, Jadva-Patel H, Jackson MT. The uptake of continuing professional development (CPD) by Ghanaian radiographers. Radiography 2011;17(4):332-344. https://doi.org/10.1016/j.radi.2011.07.002

9. Gibbs V. An investigation into the challenges facing the future provision of continuing professional development for allied health professionals in a changing healthcare environment. Radiography 2011;17(2):152-157. https:// doi.org/10.1016/j.radi.2011.01.005

10. Henwood SM, Flinton DM. 5 years on: Have attitudes towards continuing professional development in radiography changed? Radiography 2012;18(3):179-183. https://doi.org/10.1016/j.radi.2012.04.001

11. SurveyMonkey. Privacy Policy. 2013. https://www.surveymonkey.com/mp/policy/privacy-policy/ (accessed 10 October 2018).

12. Brink H, van der Walt C, van Rensburg G. Fundamentals of Research Methodology for Healthcare Professionals. 3rd ed. Cape Town: Juta, 2012.

13. Holloway I, Wheeler S. Qualitative Research in Nursing and Healthcare. 3rd ed. West Sussex, UK: WileyBlackwell, 2010.

14. Sholer H, Tonkin S, Lau KF, Law C, Rahman R, Halkett GKB. Continuing professional development: Western Australian radiographers' opinions and attitudes. Radiographer 2011;58(2):19-24. https://doi.org/10.1002/j.2051-3909.2011.tb00146.x 
15. Castillo J, Caruana CJ. Maltese radiographers' attitudes towards continuing professional development: An initial study using concept maps. J Med Imaging Radiat Sci 2014;45(1):37-46. https://doi.org/10.1016/j.jmir.2013.09.003 16. Mathers N, Mitchell C, Hunn A. A study to assess the impact of continuing professional development (CPD) on doctors' performance and patient/service outcomes for the GMC. 2012. https://www.denz.org.nz/assets/ Mathers-et-al-2013.pdf (accessed 5 November 2018).

17. Nsemo AD, John ME, Etifit RE, Mgbekem MA, Oyira EJ. Clinical nurses' perception of continuing professiona education as a tool for quality service delivery in public hospitals Calabar, Cross River State, Nigeria. Nurse Educ Prac 2013;13(4):328-334. https://doi.org/10.1016/j.nepr.2013.04.005

18. Schafheutle EI, Hassell K, Noyce PR. Ensuring continuing fitness to practice in the pharmacy workforce Understanding the challenges of revalidation. Res Soc Admin Pharm 2013;9(2):199-214. https://doi.org/10.1016 j.sapharm.2012.08.007

19. Uarije C, Daniels ER, Kalondo L, Amkongo M, Damases-Kasi C, Nabasenja C. Radiographers' attitudes towards continuous professional development (CPD) at state hospitals in Windhoek, Namibia. S Afr Radiographer 2017;55(1):18-22.
20. Summers A. Continuing professional development in Australia: Barriers and support. J Cont Educ Nurs 2015;46(8):337-339. https://doi.org/10.3928/00220124-20150721-11

1. Govranos M, Newton JM. Exploring ward nurses' perceptions of continuing education in clinical settings. Nurs Educ Today 2014;21(8):607-615

22. General Pharmaceutical Council. 2016. http://www.uptodate.org.uk/home/welcome.shtml (accessed 5 November 2018).

23. South African Institute for Chartered Accountants. 2012. https://www.saica.co.za/News/MediaKit/Publications/ ElectronicNewsletters/LearningandOpportunities18September2012/CPD/tabid/2702/language/en-US/Default. aspx (accessed 5 November 2018).

24. Pharmaceutical Society of Northern Ireland. 2016. http://cpd.psni.org.uk/manual/unit3/index.asp (accessed 5 November 2018).

Accepted 23 April 2018 